\title{
APLIKASI MOBILE HEALTH SEBAGAI INTERVENSI PROMOSI GAYA HIDUP SEHAT MENCEGAH OBESITAS ANAK: KAJIAN LITERATUR
}

\author{
Savitri Gemini ${ }^{1 *}$, Regina Natalia $^{2}$ \\ ${ }^{1 * 2}$ Program Studi Sarjana Keperawatan dan Pendidikan Profesi Ners, Institut Kesehatan Mitra Bunda \\ *Email Penulis Korespondensi: savitrigemini79@gmail.com
}

\begin{abstract}
Childhood obesity is a global problem with a continuous increase in number of cases. Therefore, changes need to be made that can reach wider and more effective based on technology. This article aims to implement a mobile health information system in Indonesia. This article uses a literature review approach from 2017-20118. Literature review conducted on nine articles that met the inclusion criteria shows that promotion and education intervention regarding obese children through mobile-health information system technology.Mobile health has been proven to effectively help change the healthy life behavior of obese children and can be applied in Indonesia especially in nursing services for obese children through promotion and education of healthy behavioral interventions.
\end{abstract}

Keywords: Child obesity; healthy life; mobile healt

\begin{abstract}
ABSTRAK
Obesitas anak adalah masalah global dengan peningkatan jumlah kasus yang terus menerus. Oleh sebab itu, perlu intervensi yang dapat menjangkau lebih luas dan efektif berbasis teknologi. Artikel ini bertujuan untuk menggali potensi penerapan teknologi sistem informasi mobile-health di Indonesia. Artikel ini menggunakan pendekatan telaah literatur tahun 2017-2018. Telaah literatur dilakukan terhadap lima artikel yang memenuhi kriteria inklusi yang menunjukkan intervensi promosi dan edukasi mengenai anak obesitas melalui sistem informasi mobile-health. Mobile-health telah teruji efektif membantu perubahan perilaku hidup sehat anak obesitas dan dapat diterapkan di Indonesia khususnya untuk lingkup pelayanan keperawatan anak obesitas berupa intervensi promosi dan edukasi perilaku hidup sehat.
\end{abstract}

Kata Kunci: Anak obesitas; hidup sehat; mobile health 


\section{PENDAHULUAN}

Obesitas merupakan kelebihan berat badan untuk tinggi badan anak yang terjadi akibat ketidakseimbangan antara kalori masuk dan kalori keluar. Obesitas sudah menjadi masalah yang Global. Hal ini tampak pada kenaikan jumlah balita yang mengalami obesitas dari tahun 2000 berjumlah 30,4 juta menjadi 40,6 juta di tahun 2016 (Unicef, WHO, \& World Bank Group, 2017). Pada tahun 2016, hampir setengah dari populasi anak-anak yang kegemukan tersebut tinggal di Asia (Unicef, WHO, \& World Bank Group, 2017). Selanjutnya di Indonesia juga menunjukkan hal yang sama pada jumlah balita yang mengalami obesitas meningkat dari 4,31\% di tahun 2016 menjadi 4,6\% di tahun 2017 (Kementerian Kesehatan RI, 2018).

Obesitas pada anak-anak dan remaja merupakan masalah yang terus meningkat di Asia Selatan (Mistry \& Puthussery, 2015). Demikian juga di Indonesia, banyak ulasan yang mengungkapkan bahwa obesitas adalah masalah kesehatan masyarakat yang serius dengan peningkatan jumlah kasus pada tiap tahun (Rachmi, Li, \& Alison Baur, 2017). Masalah kesehatan pada anak obesitas meliputi peningkatan risiko penyakit tidak menular (Unicef, WHO, \& World Bank Group, 2017) seperti asma, hipertensi, diabetes tipe II, dyslipidemia, peradangan kronis, masalah tulang dan otot (WHO, 2016), gangguan tumbuh kembang fisik dan gangguan perkembangan psikologis anak (Syahrul et al., 2016). Oleh karena itu, perlu upaya pengelolaan dini untuk mencegah obesitas yang dapat berdampak serius pada kehidupan dan dalam jangka waktu yang panjang (Kaakinen, Kyngas, \& Kaariainen, 2017).

Pengelolaan obesitas bersifat multidisiplin dimana keterlibatan perawat berperan penting dalam upaya preventif dan perawatan anak obesitas (Syahrul et al., 2016). Perawat mengelola masalah obesitas pada anak dengan cara memberikan promosi dan edukasi kesehatan tentang nutrisi yang seimbang (Syahrul et al., 2016). Hasil penelitian menunjukkan bahwa penting meningkatkan kesadaran orang tua tentang obesitas pada anak melalui promosi dan pendidikan kesehatan yang komprehensif (Syahrul et al., 2016). Perawat harus memberikan motivasi kepada anak-anak dalam perubahan gaya hidup menjadi gaya hidup sehat (Thorstensson, Blomgren, Sundler, \& Larsson, 2018).

Intervensi perubahan gaya hidup yang biasa dilakukan masih bersifat tradisional melalui konseling tatap muka sehingga membutuhkan waktu yang lama, biaya mahal dan belum dapat menjangkau jumlah yang lebih luas (Nyström et al., 2017). Untuk mengatasi hambatan tersebut maka dibutuhkan media yang dapat menyebarkan informasi secara cepat.

Perkembangan teknologi dewasa ini semakin pesat termasuk munculnya teknologi seluler yang memiliki aplikasi telepon pintar sebagai program intervensi (Nyström et al., 2017) berbasis teknologi yang dapat membantu anak obesitas menurunkan berat badan melalui gaya hidup sehat (Kaakinen et al., 2017). Pengguna teknologi telepon seluler telah menyentuh berbagai kalangan masyarakat (Efendi \& Sari, 2017) dari berbagai usia dan telah terbukti manfaatnya sebagai alat yang dapat digunakan untuk mengubah perilaku dan mengelola berat badan anak obesitas (Nyström et al., 2017) sehinga meningkatan status kesehatan. Beberapa studi tentang penggunaan mobilephone seperti intervensi MINISTOP (Mobilebased Intervention Intended to Stop Obesity in Preschoolers) melalui aplikasi smartphone (Nyström et al., 2017), aplikasi berbasis web mobile-friendly Memphis FitKids dapat diakses dengan perangkat ponsel (website http://memphisfitkids.org/) (Ullmann et al., 2018), Healthy Teens@ School (Bell 
et al., 2018), dan HAPPY ME (Yang et al., 2017) telah terbukti dapat membantu profesional kesehatan dan orang tua dalam mendukung pembentukan perilaku sehat mencegah obesitas anak.

Kajian ini bertujuan untuk menelaah penerapan penggunaan mobile health sebagai suatu intervensi khususnya intervensi keperawatan bagi anak obesitas, mengetahui manfaat dan menganalisis kelebihan, kekurangan, dan potensi penggunaannya di Indonesia. Melalui program ini diharapkan dapat meningkatan kualitas pelayanan kesehatan yang efektif dan efisien sehingga mampu menurunkan tingkat obesitas pada anak dan mempromosikan gaya hidup sehat.

\section{METODE PENELITIAN}

Penelusuran literatur untuk artikel ini menggunakan pendekatan yang sistematis dari database Google Scholar. Penelusuran artikel menggunakan kata kunci "Child", "obesity"; "healthy life", dan "mobile health". Terdapat 5 artikel terpilih dari negara meliputi Korea, Swedia, Australia, Amerika Serikat, Spanyol, Jerman. Lima artikel ini yang memenuhi kriteria yaitu artikel: berbahasa Inggris, terbit tahun 2017-2018, membahas tentang penerapan teknologi sistem informasi mobile-health dan telah teruji efektif membantu perubahan perilaku hidup sehat anak obesitas.

\section{HASIL DAN PEMBAHASAN}

Hasil penelusuran artikel dalam 2 tahun terakhir ditemukan lima artikel penelitian RCT terdapat dua artikel quasi experimental, dan satu artikel penelitian deskriptif,satu demonstarsi dan satu artikel systematic review. Setelah menelaah lima artikel, ditemukan bahwa program menggunakan penggunaan intervensi berbasis teknologi dapat mendorong anak dan remaja obesitas dan kelebihan berat badan untuk mengejar gaya hidup yang lebih sehat.

\begin{tabular}{lrlrl}
\hline \multicolumn{1}{c}{ Artikel } & \multicolumn{2}{c}{ Desain dan Sampel } & \multicolumn{2}{c}{ Intervensi yang } \\
Dilakukan
\end{tabular}




\section{Pada kelompok intervensi: mengembangkan platform HAPPY Me, yang melibatkan orang tua dan guru dalam memantau dan menyediakan lingkungan yang mendukung bagi anak-anak yang berpartisipasi. Materi pendidikan tentang kebiasaan makan yang sehat dan olahraga termasuk dalam konten platform. Platform ini menyampaikan pesan umpan balik kepada anak-anak dan orang tua. Logika aplikasi untuk pemilihan umpan balik untuk platform HAPPY ME untukorang tua dan anak berbeda sesuai dengan kebutuhan peserta .platform akan mengirimkan data PAPS dan data kinerja dari aplikasi siswa ke web untuk guru.}

Ullmann.G., Proyek demonstrasi Proyek demonstrasi tingkat Satish K. Kedia., tingkat komunitas komunitas, Memphins Ramin Sampel: 33505 pengguna Homayouni., Cem Akkus., Michael

Schmidt., Lisa M.. Klesges and Kenneth D. Ward (2018) Amerika Serikat

Nyström, C. D., Randomized pada grup Sandin, S., intervention dan kontrol

Henriksson, P., Sampel: 315 anak

Henriksson, H., Trolle-Lagerros, Y., Larsson, C.,Löf, M. (2017). Fitkids dikembangkan dan diterapkan di Area Memphins. Aplikasi TAS ini dirancang bagi orang tua untuk menilai resiko obesitas anak melalui faktor penentu seperti berat badan, diet, aktivitas fisik, waktu layar dan kecukupan tidur.

Anak yang diambil 315 secara acak dimasukkan kedalam kelompok intervensi dan kontrol.orang tua dalam kelompok intervensi menerima perbedaan yang program 6-mo mHealth. signifikan antara Hasil utama adalah indeks kelompok massa lemak (FMI), intervensi dan sedangkan hasil sekunder kontrol 
Bell, M. J., randomized controlled Peserta dari kelompok Zeiler, M., trial (RCT) intervensi ditugaskan ke

Herrero, R., Sampel: siswa berusia salah satu dari dua jalur

Kuso, S., Nitsch, 14-19 tahun

M., Etchemendy, E., Waldherr, K.

(2018).

Austria

program yang mungkin berdasarkan hasil penilaian online awal. Program yang dibuat adalah Program HealthyTeens@ School.
Kaakinen, P., Descriptive systematic Kyngas, H., \& literature review Kaariainen, $M$. (2017). adalah asupan buah-buahan,

sayuran, permen dan minuman manis serta waktu yang dihabiskan untuk aktifitas fisik sedang dan berat. Remaja yang berlebihan berat badan ditugaskan kejalur manajemen berat badan yang menekankan makan seimbang dan olahraga untuk tenance utama berat badan. Peserta mengerjakan sepuluh modul (satu modul 20-30 menit perminggu) selama jam sekolah atau dirumah. Penilaian dilakukan sebelum dan sesudah intervensi dan pada 6 dan 12bulan setelah penilaian awal.

Mendeskripsikan intervensi konseling berbasis teknologi dalam mendukung anak dan remaja obesitas atau kelebihan berat badan untuk mengubah berat badan/gaya hidup.
Program Healthy Teens@School dapat mencegah obesitas dan gangguan makan dikalangan remaja.
Dari systematic literature review ini tampak penggunaan intervensi konseling berbasis teknologi dapat mendorong anak dan remaja obesitas dan kelebihan berat badan untuk mengejar gaya hidup yang lebih sehat
Masalah obesitas melibatkan professional dari berbagai disiplin ilmu. Pengembangan aplikasi berbasis mobile health di beberapa Negara bertujuan untuk mencegah gangguan makan pada anak obesitas (Bell et al., 2018) dan 
mempromosikan perilaku hidup sehat yaitu fokus pada nutrisi atau diet, aktivitas fisik, dan tidur (Nyström et al., 2017; Ullmann et al., 2018; Yang et al., 2017). Beberapa program yang termasuk dalam intervensi online yang dapat diakses melalui smartphone seperti Memphis FitKids (Tennessee), Healthy Teens @ School (Australia dan Spanyol), dan StayingFit (Amerika Serikat) telah dikembangkan untuk meningkatkan perilaku hidup sehat pada sasaran dalam wilayah yang lebih luas dengan populasi yang besar (Bell et al., 2018; Ullmann et al., 2018). Program tersebut menggunakan akun pribadi yang dapat login menggunakan alamat email dan kata sandi pribadi (Bell et al., 2018; Ullmann et al., 2018) sehingga data pengguna yang disimpan pada situs web terjaga kemanannya (Ullmann et al., 2018).

Kinerja mobile health sebagai alat akses pengguna dapat dibuktikan dengan kemampuannya menyimpan data tentang antropometri, asupan atau kebiasaan diet (vitamin, makanan dan minuman manis), aktifitas fisik, istirahat dan status kesehatan anak (Bell et al., 2018; Ullmann et al., 2018; Nyström et al., 2017; Yang et al., 2017). Data tersebut diinput oleh anak atau orang tua setiap hari atau satu kali seminggu untuk dipantau hasilnya sebagai pedoman penyusunan diet dan basis data back end dokumentasi laporan yang dapat dikirim langsung ke email tenaga kesehatan yang terlibat dalam pengelolaan obesitas anak (Ullmann et al., 2018). Kemudian orang tua menerima tanggapan dari ahli gizi, perawat, atau tenaga kesehatan lain dan orang tua dapat memberikan umpan balik dengan mengajukan pertanyaan yang berkaitan dengan kesehatan anak (Nyström et al., 2017).

Aplikasi mHealth membantu penilaian perilaku sehat melalui fungsi menu yang tersedia. Seperti pada aplikasi Memphis FitKids dapat memiliki menu FitCheck untuk menilai diet, tidur, dan aktivitas (Ullmann et al., 2018). Sedangkan pada Healthy Teens @ School menyediakan fungsi Tugas, Kontak, dan Buku Harian. Perintah "Tugas" berisi modul-modul tentang program mencegahan obesitas (kebiasaan sehat dan pengelolaan berat badan), sedangkan perintah "Kontak" dapat digunakan jika ingin menghubungi tenaga kesehatan secara anonim untuk mendiskusikan masalah (Bell et al., 2018).

Selanjutnya, aplikasi mHealth dapat didesain lebih baik untuk meningkatkan kinerja dan kenyaman pengguna. Terdapat opsi healthy weight, healthy habits, dan healthy community serta penambahkan disclaimer, grafik, warna, dan pilihan untuk mencetak, mengirim email, dan menyimpan laporan pada desain laporan FitCheck dapat memudahkan orang tua memantau berat badan, perilaku, dan komunitas yang sehat bagi anak (Ullmann et al., 2018). Pada aplikasi HAPPY ME dilengkapi dengan fungsi mengirimkan pesan sehingga membantu anak mengingat kebiasaan yang mendukung untuk kesehatan seperti olahraga, sarapan pagi, konsumsi buah dan sayur, dan hindari makanan instan (Yang et al., 2017). Mode pengingat dikirim melalui SMS atau $e$ mail yang bertujuan untuk meningkatkan kepatuhan terhadap perilaku hidup sehat anak (Bell et al., 2018). Selain itu, perangkat mHealth dapat dibuat tersambung dengan Walkie + D Coffee melalui koneksi Bluetooth sehingga data dari Walkie D Coffee meliputi aktivitas fisik, intensitas latihan, hitungan langkah, dan jumlah kalori yang dikeluarkan dengan berjalan atau berlari dikirim ke smartphone anak (Yang et al., 2017).

Suatu aplikasi dapat dipercaya keefektifannya mencegah obesitas anak jika pedoman, modul-modul dan informasi yang dibagikan dalam bentuk grafik, video, dan komentar berdasarkan rekomendasi nutrisi dan aktifitas yang berlaku secara nasional. Aplikasi 
Memphis FitKids telah menyusun pedoman diet dan tidur berdasarkan pada rekomendasi dari Pusat Nasional Pencegahan Penyakit Kronis dan Promosi Kesehatan, Pedoman Departemen Kesehatan dan Pelayanan, dan Departemen Pertanian AS (Ullmann et al., 2018). Sehingga program yang dijalankan dalam aplikasi mHealth dapat terjamin kelayakan informasinya bagi pengguna.

Aplikasi mHealth telah terbukti bermanfaat sebagai intervensi pengendali obesitas anak yang dapat meningkatkan kerjasama orang tua, tenaga kesehatan dan guru. Dalam hal ini, anak adalah individu yang akan menyelesaikan tugas sesuai pedoman aplikasi mHealth. Orang tua dapat memantau perilaku anak dan akan mendapat pesan pengingat dari aplikasi selain itu, banyak pengetahuan yang dapat memandu orang tua berperan dalam menciptakan lingkungan yang mendukung bagi pencegahan obesitas anak (Yang et al., 2017). Dalam lingkungan sekolah, guru berperan untuk memotivasi anak meningkatkan perilaku sehat. Konten web yang dapat diakses guru memuat pengetahuan tentang nutrisi dan aktifitas fisik dan dimodifikasi agar lebih tepat untuk mengajarkan kurikulum yang berhubungan dengan kesehatan (Yang et al., 2017).

Dengan demikian, setelah terbentuk kerjasama yang baik, keberhasilan suatu intervensi membutuhkan peran penting dari tenaga kesehatan seperti perawat. Perawat memainkan peran dalam mencegah dan memberikan intervensi kepada anak dan harus mengetahui gaya hidup anak dan keluarga serta faktor risiko obesitas (Syahrul et al., 2016). Intervensi pencegah obesitas yang diberikan perawat dan tenaga kesehatan lain dapat efektif dan efisien dengan menggunakan mHealth. Hal ini sebagai bukti pemanfaatan teknologi dalam keperawatan dapat menjadi solusi bagi masalah obesitas anak.
Mobile Health belum teruji keefektifannya dalam menurunkan massa lemak tubuh dan indeks massa tubuh secara langsung, namun lebih pada metode penurunan berat badan yang menekankan perubahan perilaku sehat. Pengembangan aplikasi mHealth bertujuan untuk meningkatkan kesadaran orang tua terhadap perilaku sehat, memberikan informasi tentang gaya hidup sehat, meningkatkan kesehatan, dan mengurangi obesitas anak (Ullmann et al., 2018). Sity mHealth onlinethos

هishealth

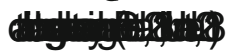

Aplikasi mHealth Memphis FitKids dapat mempermudah orang tua menerima informasi yang berguna bagi kesehatan anak (ht)

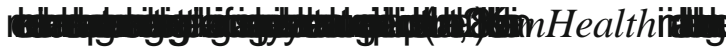
Facebook mahasiswa pascasarjana Sekolah Studi Kesehatan dan Sekolah Kesehatan Masyarakat di Universitas Memphis. Meskipun demikian, orang tua merasa senang mendapat kesempatan untuk mengomentari tulisan dan mengirim pesan secara anonim sehingga privasi terlindungi

Penerapan teknologi mHealth sebaiknya juga memperhatikan karakteristik anak sesuai tingkat pertumbuhan dan perkembangan anak. Suatu aplikasi yang dapat meningkatkan motivasi anak melalui pemberian penghargaan diterapkan dalam aplikasi mHealth HAPPY ME dimana terdapat elemen gamification ke aplikasi sehingga anak-anak mendapat poin jika berhasil menyelesaikan tugas yang mengarah pada hasil akhir yaitu peningkatan kebugaran kesehatan (Yang et al., 2017). Hal itu merupakan pencapaian yang penting dalam mengontrol perilaku untuk memperoleh berat badan yang sehat dalam jangka panjang (Yang et al., 2017).

Amerika Serikat, Jerman, Spanyol, dan Australia telah mengembangkan 
teknologi mHealth dalam manajemen pengendalian berat badan bagi anak obesitas. Melihat tanggapan baik pengguna mobile healt, menjadi gambaran bahwa mHealth berpotensi dikembangkan untuk jangkauan yang luas seperti di Indonesia. Indonesia adalah negara kepulauan yang dapat mempengaruhi penyebaran tenaga kesehatan dan cakupan pelayanan kesehatan. Prevalensi anak obesitas yang ada di berbagai wilayah terutama wilayah yang terpencil butuh akses untuk aliran informasi kesehatan. Meskipun terdapat perbedaan infrastruktur kota besar dengan pedesaan (Bond, Hacking, Milosevic, \& Zander, 2013; dalam Efendi \& Sari, 2017). Kebutuhan masyarakat akan pelayanan kesehatan yang merata dan berkualitas dapat dipenuhi dengan penggunaan teknologi mutahir mHealth yang berfokus pada pelayanan promosi kesehatan anak obesitas.

Perbedaan tingkat sosial dan demografi di berbagai wilayah Indonesia dapat menimbulkan tanggapan yang berbeda pada teknologi baru. Sehingga diperlukan upaya edukasi yang komprehensif dari tenaga kesehatan khususnya perawat dan dukungan kebijakan dari pemerintah pusat dan daerah.

Meskipun mHealth memiliki manfaat dan dapat di terapkan di Indonesia, namun pengaturan elemen yang ada dalam suatu aplikasi sebaiknya menyesuaikan dengan karakteristik masyarakat dan budaya di Indonesia serta masukan dari stakeholder (Bell et al., 2018). Modifikasi dan alih bahasa menjadi perlu untuk dipertimbangkan jika program mHealth yang diadopsi akan menyentuh target pada kelompok sosial ekonomi rendah yang cenderung kurang dalam segi pendidikan, pengetahuan dan penguasaan

\section{DAFTAR PUSTAKA}

Bell, M. J., Zeiler, M., Herrero, R., Kuso, S., Nitsch, M., Etchemendy, E., ... bahasa asing. Pemantauan informasi yang disebarkan melalui aplikasi yang dapat terhubung ke Youtube dan Facebook perlu pengawasan yang ketat untuk menjamin informasi berkualitas dari profesional kesehatan yang mampu mempertahankan perilaku sehat. Sehingga hasil akhir yang diharapkan dari penerapan teknologi mHealt dapat menurunkan obesitas anak dapat tercapai.

\section{SIMPULAN}

Pelayanan kesehatan pada anak obesitas sebaiknya berfokus pada upaya pencegahan obesitas melalui perilaku hidup sehat. Dalam upaya mempromosikan perilaku hidup sehat perlu koordinasi antara orang tua, guru, dan tenaga kesehatan khususnya perawat. Orang tua dan guru dapat membantu perawat dan tenaga kesehatan lain mengawasi perilaku sehat anak sehingga anak akan termotivasi dan patuh dalam menjalani kebiasaan hidup sehat.

Perkembangan teknologi informasi berbasis mobile online memberikan manfaat dan kemudahan bagi anak dan keluarga untuk berhubungan dengan perawat dan tim kesehatan lainnya dalam pengadopsian perilaku. Melalui sistem ini, peran orang tua, guru, dan tenaga kesehatan dapat lebih ditingkatkan sehingga pelayanan yang diberikan akan berkualitas. Oleh sebab itu, diharapkan mobile health mulai diterapkan di Indonesia khususnya untuk lingkup pelayanan keperawatan anak obesitas berupa intervensi promosi dan edukasi perilaku hidup sehat.

\section{UCAPAN TERIMAKASIH}

Terima kasih penulis ucapkan kepada institusi dan teman yang telah membantu penyelesaian penelitian ini

Waldherr, K. (2018). Healthy Teens @ School: Evaluating and 
disseminating transdiagnostic preventive interventions for eating disorders and obesity for adolescents in school settings. Internet Interventions, (February), 1-11. https://doi.org/10.1016/j.invent.2018. 02.007 .

Efendi, D., \& Sari, D. (2017). Pelayanan keperawatan anak dengan penyakit kronis pada seting home hospital: Kajian literatur. Jurnal Keperawatan Indonesia, 20(1), 1-8. https://doi.org/10.7454/jki.v20i1.44.

Kaakinen, P., Kyngas, H., \& Kaariainen, M. (2017). Technology based counseling in the management of weight and lifestyles of obese or overweight children and adolescents: A descriptive systematic literature review. Informatics for Health and Social Care, 43(2), 126-141. https://doi.org/10.1080/17538157.20 17.1353997.

Kementerian Kesehatan RI. (2018). Data dan Informasi Kesehatan Profil Kesehatan Indonesia 2017. Kementerian Kesehatan RI. Jakarta.

Mistry, S.K., Puthussery, S. (2015). Risk factors of overweight and obesity in childhood and adolescence in South Asian countries: A systematic review of the evidence. Public Health, 129(3), 200-209. https://doi.org/10.1016/j.puhe.2014.1 2.004.

Nyström, C. D., Sandin, S., Henriksson, P., Henriksson, H., Trolle-Lagerros, Y., Larsson, C., ... Löf, M. (2017). Mobile-based Intervention Intended to Stop Obesity in preschool-aged children: The MINISTOP randomized controlled trial. American Journal of Clinical Nutrition, 105(6), 1327-1335. https://doi.org/10.3945/ajcn.116.150 995.

Rachmi, C. N., Li, M., \& Alison Baur, L. (2017). Overweight and obesity in Indonesia: prevalence and risk factors - a literature review. Public Health, 147, 20-29. https://doi.org/10.1016/j.puhe.2017.0 2.002 .

Syahrul, S., Kimura, R., Tsuda, A., Susanto, T., Saito, R., \& Ahmad, F. (2016). Prevalence of underweight and overweight among school-aged children and it's association with children's sociodemographic and lifestyle in Indonesia. International Journal of Nursing Sciences, 3(2), 169-177.

https://doi.org/10.1016/j.ijnss.2016.0 4.004 .

Thorstensson, S., Blomgren, C., Sundler, A. J., \& Larsson, M. (2018). To Break the weight gain - A qualitative study on the experience of School nurses working with overweight children in elementary school. Journal of Clinical Nursing, 27(1-2), e251-e258.

https://doi.org/10.1111/jocn.13924.

Ullmann, G., Kedia, S. K., Homayouni, R., Akkus, C., Schmidt, M., Klesges, L. M., \& Ward, K. D. (2018). Memphis itKids: Implementing a mobile-friendly web-based application to enhance parents' participation in improving child health. BMC Public Health, 18(1), 1-12. https://doi.org/10.1186/s12889-018-59686.

Unicef, WHO, \& World Bank Group. (2017). Levels and trends in child malnutrition. Retrieved from http://www.who.int/nutgrowthdb/jme _brochoure2017.pdf?ua=1.

WHO. (n.d.). Consideration of the evidence on childhood obesity for the commission on ending childhood obesity report of the ad hoc working group on science and evidence for ending childhood obesity. Retrieved from

http://apps.who.int/iris/bitstream/10665 1\%0A206549/1/9789241565332_eng.p df. 
Yang, H. J., Kang, J. H., Kim, O. H., Choi, M., Oh, M., Nam, J., \& Sung, E. (2017). Interventions for preventing childhood obesity with smartphones and wearable device: A protocol for a non-randomized controlled trial. International Journal of Environmental Research and Public Health, 14(2).110.

https://doi.org/10.3390/ijerph14020184 